\title{
Relationship between blood pressure response during hemodialysis and exercise tolerance or heart rate recovery measured using cardio-pulmonary exercise testing in maintenance hemodialysis patients
}

\author{
Hiroki Yabe ${ }^{1,2^{*}}$ (D) Kenichi Kono ${ }^{3}$, Ryota Shiraki ${ }^{4}$, Akiho Masuda ${ }^{2}$, Yoshifumi Moriyama ${ }^{4}$ and Hirotake Kasuga ${ }^{5}$
}

\begin{abstract}
Background: This study investigated the association between the blood pressure response during hemodialysis (HD) and exercise tolerance or heart rate recovery (HRR) measured with cardiopulmonary exercise testing (CPX).

Methods: The study enrolled 23 patients who had been undergoing 4-h regular maintenance HD. The maximum workload $\left(\right.$ Load $\left._{\text {peak }}\right)$, peak oxygen uptake $\left(\mathrm{VO}_{2 \text { peak }}\right)$, workload and oxygen uptake at the anaerobic threshold ( Load $_{\mathrm{AT}}$ and $\mathrm{VO}_{2 \mathrm{AT}}$, respectively), and HRR were measured with CPX. The average systolic blood pressure during HD ( $\mathrm{SBP}_{\mathrm{av}}$ ) was measured, and the number of times the SBP was less than $100 \mathrm{mmHg}$ was determined in the 2-week period after CPX.

Results: The SBP av showed a significant correlation with $\operatorname{Load}_{\text {AT }}(r=0.46)$ and $\operatorname{Load}_{\text {peak }}(r=0.43, p<0.05)$. The number of times the SBP was less than $100 \mathrm{mmHg}$ showed a significant correlation with the HRR $(r=-0.44, p<$ 0.05).
\end{abstract}

Conclusion: Exercise intolerance and HRR in HD patients may be associated with blood pressure instability during HD.

Keywords: Blood pressure instability, Cardio-pulmonary exercise testing, Exercise tolerance, Heart rate recovery, Hemodialysis

\section{Introduction}

The most frequent and serious side effect of hemodialysis (HD) is intradialytic hypotension (IDH) [1], which is estimated to occur in $15 \%$ to $30 \%$ of all HD treatments [2,3] and is an independent risk factor for mortality [4]. The main causes of IDH have been reported to include acute hypovolemia during ultrafiltration and inadequate compensatory mechanisms [5] associated with inadequate dry weight setting, hypoalbuminemia that induces the reduction of the plasma

\footnotetext{
* Correspondence: yabe0909@gmail.com

${ }^{1}$ Department of Physical Therapy, School of Rehabilitation Sciences, Seirei Christopher University, 3453 Mikatahara, Kita-ku, Hamamatsu 433-8558, Japan ${ }^{2}$ Department of Rehabilitation, Nagoya Kyoritsu Hospital, Nagoya, Japan Full list of author information is available at the end of the article
}

refilling rate, reduced cardiac function, and abnormalities in the autonomic nervous system [6]. Assuming that the dry weight and albumin levels are managed appropriately, it is hypothesized that blood pressure changes can occur with ultrafiltration when the cardiovascular and autonomic responses cannot compensate for large volume losses.

Blood pressure responses are associated with exercise tolerance [7]. The peak oxygen uptake $\left(\mathrm{VO}_{2}\right)$, which is one of the exercise tolerance parameters measured by cardio-pulmonary exercise testing (CPX), may affect the blood perfusion to the peripheral tissues because it indicates not only the ability for oxygen utilization (arterialvenous $\mathrm{O}_{2}$ difference) but also oxygen supply (cardiac output). Previous studies have shown that the exercise 
tolerance rate in HD patients is $\sim 50-60 \%$ of that in normal subjects $[8,9]$ and that left ventricular (LV) function in $\mathrm{HD}$ patients is also decreased [10, 11]. Moreover, HD patients have an autonomic dysfunction [12], which is even more common in patients with uremia and IDH $[12,13]$. These data suggest that the exercise intolerance in HD patients leads to instability of blood pressure through poor blood perfusion in the peripheral tissues resulting from a decreased vascular function due to autonomic dysfunction. However, to our knowledge, only a few studies have investigated the relationship between exercise tolerance and IDH. To elucidate the factors affecting the pathological response of IDH, firstly, it is necessary to clarify the relationship between exercise and the near-normal blood pressure response by ultrafiltration.

The purpose of this study is to assess the relationship between exercise tolerance and blood pressure response during HD. Moreover, the heart rate recovery (HRR) was measured using CPX and calculated from the absolute difference between the peak heart rate $(\mathrm{HR})$ and $\mathrm{HR}$ in 1 min of recovery, which reflects the autonomic function. Exercise tolerance and the HRR may reflect the blood pressure response during HD.

\section{Materials and methods}

\section{Patients}

Twenty-three patients with chronic kidney disease who had been undergoing 4-h regular maintenance HDs, three times per week for $>2$ years, were enrolled. The following patients were excluded from this study: patients with serious hypotension at least 1 month prior to this study, including symptomatic hypotension and/or requiring cessation of fluid removal or treatment with medication, and patients who have contraindications for exercise testing according to cardiovascular disease established guidelines for rehabilitation [14] (e.g., acute myocardial infraction, uncontrolled unstable angina pectoris, and uncontrolled arrhythmia), severe morbid obesity (body mass index (BMI) of $>30 \mathrm{~kg} / \mathrm{m}^{2}$ ), moderate or severe heart valve insufficiency and/or stenosis, history of stroke, chronic obstructive pulmonary disease, and orthopedic or musculoskeletal disorder. Patients taking beta blockers were also excluded to exclude the influence on the HR during exercise. This study conformed to the provisions of the Declaration of Helsinki, and written informed consent was obtained from all participants. The study was approved by the Nagoya Kyoritsu Hospital Ethical Committee (K118-02).

\section{Exercise testing}

Symptom-limited CPX was performed using a cycle ergometer (STB-1400, NIHON KOHDEN, Tokyo, Japan) according to a ramp protocol. After resting for $3 \mathrm{~min}$ on the cycle ergometer, exercise was started with an increment of load of $10 \mathrm{watt} / \mathrm{min}$ following a 3-min warm-up period. Twelve-lead ECG findings were continuously monitored. The HR and systolic and diastolic blood pressures (SBP and DBP) were monitored every $1 \mathrm{~min}$ during the testing. $\mathrm{VO}_{2}$, carbon dioxide production, and tidal volume were measured using a breath-by-breath method and an expired gas analyzer (AE310s, MINATO, Tokyo, Japan) during CPX. The endpoint of CPX was determined in accordance with the criteria of the American College of Sports Medicine. CPX performed the evaluation on inter-dialytic days. None of the patients showed ischemic ECG changes during CPX.

The maximal symptom-limited workload ( $\operatorname{Load}_{\text {peak }}$ ) was defined as the highest work level reached. Peak $\mathrm{VO}_{2}$ $\left(\mathrm{VO}_{2 \text { peak }}\right)$ was considered as the highest $\mathrm{VO}_{2}$ obtained. The anaerobic threshold was defined using the v-slope method, and $\mathrm{VO}_{2}\left(\mathrm{VO}_{2 \mathrm{AT}}\right)$ and workload at $\left(\operatorname{Load}_{\mathrm{AT}}\right)$ were measured. The HR at rest, AT, and peak exercise $\left(\mathrm{HR}_{\text {peak }}\right)$ were determined from the $\mathrm{HR}$ recorded during CPX. In addition, the HRR at the time of constant HR decay for the first $60 \mathrm{~s}$ of the recovery period $\left(\mathrm{HR}_{60}\right)$ was calculated as follows:

$$
\mathrm{HRR}=\mathrm{HR}_{\text {peak }}-\mathrm{HR}_{60}
$$

\section{Clinical characteristics}

The clinical characteristics obtained from the patient medical records included age, sex, BMI, duration of HD, and dry body weight. The LV ejection fraction (EF), LV end-diastolic dimension (LVDd), and LV end-systolic dimension (LVDs) measured by echocardiography and blood samples (total protein, albumin, sodium, potassium, phosphate, calcium, hemoglobin, and hematocrit) were obtained before the day of CPX. Body weight at pre-HD $\left(\mathrm{BW}_{\text {pre }}\right)$ and post-HD (BW post), body weight gain during the HD interval, body fluid removal, and body fluid removal rate were measured at each HD session, and the values for over 2 weeks were averaged.

\section{Intradialytic blood pressure measurements}

Intradialytic blood pressure was measured on the same arm in the supine position at 1-h intervals (at the start of dialysis and four times during dialysis: a total of five times in one HD session) using an automated sphygmomanometer over 2 weeks from the next HD session after $\mathrm{CPX}$. The average SBP $\left(\mathrm{SBP}_{\mathrm{av}}\right)$ was calculated over a total of 30 measurement times (five times during one HD session $\times$ three times/week $\times 2$ weeks). In reference to several previously reported studies $[4,15,16]$, we measured the number of times the SBPs became less than $100 \mathrm{mmHg}$ over 2 weeks and recorded it as the blood pressure response. 


\section{Statistical analysis}

All continuous data were summarized as means \pm SD and categorical data as numbers (\%). The association between blood pressure instability $\left(\mathrm{SBP}_{\mathrm{av}}\right.$ and the number of times the SBPs became less than $100 \mathrm{mmHg}$ over the 2 weeks) and exercise tolerance $\left(\mathrm{VO}_{2 \mathrm{AT}}, \mathrm{VO}_{2 \text { peak }}\right.$, Loa$\mathrm{d}_{\mathrm{AT}}$, and $\operatorname{Load}_{\text {peak }}$ ), HRR, and cardiac function (EF, LVDd, LVDs), HD conditions (BW $\mathrm{BW}_{\text {pre }} \mathrm{BW}$ gain and gain rate of HD interval, fluid removal, ultrafiltration rate), laboratory data (total protein and albumin) were assessed. Either Pearson's or Spearman's correlation coefficients were used depending on whether variables were normally distributed or not. Coefficient values of $p<0.05$ were considered statistically significant. Statistical analyses were performed using SPSS version 23.0 for Windows (IBM, Tokyo Japan).

\section{Results}

The demographic features, clinical laboratory variables, echocardiography variables, and usage of drugs by the subjects are shown in Table 1 . The measured values of exercise tolerance $\left(\mathrm{VO}_{2 \mathrm{AT}}, \mathrm{VO}_{2 \text { peak }}\right.$, Load ${ }_{\mathrm{AT}}$, and Loadpeak), HRR, HD condition ( $\mathrm{BW}_{\text {pre }}, \mathrm{BW}_{\text {post }}$, body weight gain at HD interval, body fluid removal, and body fluid removal rate), and blood pressure response $\left(\mathrm{SBP}_{\mathrm{av}}\right.$, number of patients with SBPs of less than $100 \mathrm{mmHg}$, and number of times the SBPs became less than $100 \mathrm{mmHg}$ ) are shown in Table 2. No serious hypotension, including symptomatic hypotension, requiring cessation of fluid removal or treatment with medication, was observed during this study.

The correlation coefficients between the blood pressure response and exercise tolerance, HRR, and cardiac function are presented in Table 3. The $\mathrm{SBP}_{\mathrm{av}}$ that showed a significant correlation was $\operatorname{Load}_{\mathrm{AT}}(r=0.46, p$ $<0.05)$ and $\operatorname{Load}_{\text {peak }}(r=0.43, p<0.05)$. The relationship between the $\mathrm{SBP}_{\mathrm{av}}$ and HRR was not significant $(r=$ 0.39 ); however, there was a strong trend, with a $p$ value of 0.06 . The number of times the SBPs became less than $100 \mathrm{mmHg}$ had a significant correlation with the HRR $(r$ $=-0.44, p<0.05)$. No significant relationship between the HD conditions, the cardiac function measured by echocardiography, laboratory data, and the blood pressure response was observed.

\section{Discussion}

The main finding of this study is that exercise tolerance measured by the exertion of load at and peak exercise and the HRR are correlated with blood pressure response during HD in patients with no obvious hypotension. A previous study reported that for the examined relationship between the lowest intradialysis BP and mortality, after adjustment for known prognostic factors, the odds ratio for SBP between
Table 1 Subject characteristics

\begin{tabular}{|c|c|}
\hline & Mean \pm SD \\
\hline Age (year) & $65.3 \pm 10.2$ \\
\hline Sex (men/women) & $12 / 11$ \\
\hline Height $(\mathrm{cm})$ & $157.8 \pm 8.9$ \\
\hline Dry weight (kg) & $55.5 \pm 13.8$ \\
\hline $\mathrm{BMI}\left(\mathrm{kg} / \mathrm{m}^{2}\right)$ & $22.8 \pm 4.2$ \\
\hline \multicolumn{2}{|l|}{ History of disorder (n (\%)) } \\
\hline Diabetes & $9(39.1)$ \\
\hline Hypertension & $18(78.2)$ \\
\hline Angina pectoris & $6(26.1)$ \\
\hline Hyperlipidemia & $6(26.1)$ \\
\hline \multicolumn{2}{|l|}{ Laboratory data } \\
\hline Total protein & $6.9 \pm 0.7$ \\
\hline Albumin & $3.6 \pm 0.4$ \\
\hline Sodium & $136.8 \pm 3.7$ \\
\hline Potassium & $4.4 \pm 0.7$ \\
\hline Phosphorus & $5.2 \pm 09$ \\
\hline Calcium & $9.1 \pm 0.6$ \\
\hline Hemoglobin & $10.9 \pm 1.3$ \\
\hline Hematocrit & $33.6 \pm 4.1$ \\
\hline \multicolumn{2}{|l|}{ Echocardiography } \\
\hline EF (\%) & $66.4 \pm 11.7$ \\
\hline LVDd (mm) & $47.5 \pm 7$ \\
\hline LVDs (mm) & $29 \pm 6.6$ \\
\hline \multicolumn{2}{|l|}{ Medicine (n (\%)) } \\
\hline Calcium antagonist & $10(43.5)$ \\
\hline ACE inhibitor & $1(4.3)$ \\
\hline ARB & $7(30.4)$ \\
\hline Amezinium metilsulfate & $2(8.8)$ \\
\hline Droxidopa & $1(4.3)$ \\
\hline
\end{tabular}

$A R B$ angiotensin II receptor blocker, $E F$ ejection fraction, $L V D s$ left ventricular end-systolic dimension, LVDd left ventricular end-diastolic dimension

110 and $119 \mathrm{~mm} \mathrm{Hg}$ was significantly associated with mortality compared with $130-139 \mathrm{mmHg}$ as a reference [4]. Additionally, a previous review on IDH showed that the highest mortality risks associated with IDH were observed when the intradialytic systolic blood pressure nadirs were $<90$ and $<100$ $\mathrm{mmHg}[16]$. This study defined blood pressure instability as a low level of systolic blood pressure with ultrafiltration of hemodialysis, differing from previous studies that showed an obvious IDH. However, as previous studies have shown that low blood pressure levels are associated with a significantly worse prognosis, the indicator of $<100 \mathrm{mmHg}$ pressure and average systolic blood pressure adopted in this study may have clinical significance as blood pressure instability. 
Table 2 Exercise tolerance and HD condition

Mean \pm SD

Exercise tolerance

$V_{\text {2AT }}(\mathrm{ml} / \mathrm{min} / \mathrm{kg})$

$9.3 \pm 2.2$

$\operatorname{Load}_{\mathrm{AT}}$ (watt)

$37.1 \pm 9.8$

$\mathrm{VO}_{\text {2peak }}(\mathrm{ml} / \mathrm{min} / \mathrm{kg})$

$12.8 \pm 4.2$

Load $_{\text {peak }}$ (watt)

$54.3 \pm 19.5$

HRR (bpm)

$6.4 \pm 6.1$

HD condition

$\mathrm{BW}_{\text {pre }}(\mathrm{kg})$

$57.1 \pm 13.5$

BW gain of HD interval $(\mathrm{kg})$

$1.9 \pm 0.7$

BW gain of HD interval (\%)

$3.5 \pm 1.2$

Fluid removal (L)

Ultrafiltration rate $(\mathrm{L} / \mathrm{h})$

$2.1 \pm 0.7$

$0.53 \pm 0.16$

Blood pressure response

$\mathrm{SBP}_{\mathrm{av}}(\mathrm{mmHg})$

Number of hypotension (SBP less than $<100 \mathrm{mmHg}$ ) (n)

6 times

3 times

2 times

1 time

Total

2

7

Number of hypotension (SBP less than $<100 \mathrm{mmHg}$ ) (times/patient)

$A T$ anaerobic exercise threshold, $H R R$ heart rate recovery, $B W$ body weight, $B W_{\text {pre }}$ body weight at before $H D, B W_{\text {post }}$ body weight at after $H D, S B P_{a v}$ average systolic blood pressure over 6 times HD session

Table 3 Correlation between blood pressure response during HD and exercise tolerance or cardiac function

\begin{tabular}{|c|c|c|c|c|}
\hline & $R$ & & & \\
\hline & $\mathrm{SBP}_{\mathrm{av}}$ & $p$ & Number of hypotension (SBP < $100 \mathrm{mmHg}$ ) & $p$ \\
\hline$\overline{\text { Age }}$ & -0.39 & n.s. & 0.14 & n.s. \\
\hline $\mathrm{BMl}$ & 0.13 & n.s. & -0.1 & n.s. \\
\hline BW gain of HD interval & 0.35 & n.s. & 0.3 & n.s. \\
\hline Fluid removal & -0.24 & n.s. & 0.29 & n.s. \\
\hline Ultrafiltration rate & -0.23 & n.s. & -0.2 & n.s. \\
\hline Total protein & 0.90 & n.s. & 0.32 & n.s. \\
\hline Albumin & 0.33 & n.s. & -0.90 & n.s. \\
\hline $\mathrm{EF}$ & 0.01 & n.s. & 0.16 & n.s. \\
\hline LVDd & 0.19 & n.s. & 0.04 & n.s. \\
\hline LVDs & 0.17 & n.s. & 0.25 & n.s. \\
\hline $\mathrm{VO}_{2 \mathrm{AT}}$ & 0.22 & n.s. & -0.40 & n.s. \\
\hline $\operatorname{Load}_{\text {AT }}$ & 0.46 & $<0.05$ & -0.22 & n.s. \\
\hline $\mathrm{VO}_{2 \text { peak }}$ & 0.17 & n.s. & -0.27 & n.s. \\
\hline Load $_{\text {peak }}$ & 0.43 & $<0.05$ & -0.22 & n.s. \\
\hline HRR & 0.39 & 0.06 & -0.44 & $<0.05$ \\
\hline
\end{tabular}

$S B P_{a v}$ average systolic blood pressure over 6 times $\mathrm{HD}$ session, $A T$ anaerobic exercise threshold, $H R R$ heart rate recovery, EF ejection fraction, $L V D s$, left ventricular end-systolic dimension, LVDd left ventricular end-diastolic dimension 
The blood pressure response during HD is regulated by several mechanisms. It is well-demonstrated that acute hypotension observed during HD develops as a result of hypovolemia and inadequate compensatory mechanisms to counter the reduced intravascular volume $[5,13]$. The Japanese clinical guidelines for the cardiovascular complications in HD patients [6] demonstrate that the cause of IDH is an inadequate dry weight setting, hypoalbuminemia that induces the reduction of the plasma refilling rate, reduced cardiac function, and abnormalities in the autonomic nervous system. A previous study has shown that ischemic heart disease and LV systolic dysfunction [17] were the main predictors of hemodynamic instability. However, the present study includes no uncontrolled patient who had severe LV dysfunction (EF of $66.4 \pm 11.7 \%$, Table 1 ) and inadequate body weight gain (average weight gain including 2 days of HD interval of $3.5 \pm 1.2 \%$, Table 2 ). Additionally, this study shows not only a correlation between the HD conditions and albumin levels, but also LV function and blood pressure responses during HD (Table 3). Previous studies have shown that the measures of LV performance obtained at rest did not accurately reflect exercise capacity in patients with chronic heart failure [18] and that changes in the EF at pre- to mid-dialysis periods, which do not reflect the absolute value of the EF, were significantly associated with IDH [19]. These studies suggested that the instability of blood flow was associated with not only the LV function at rest but also capabilities in dynamic regulation, such as compensation in the LV systolic function, $\mathrm{VO}_{2}$, and $\mathrm{HR}$ during exercise. Although the control of blood pressure during $\mathrm{HD}$ is a complex process resulting from the interaction of several mechanisms, these data suggest that blood perfusion instability is associated with exercise intolerance and an autonomic nervous system response.

HD patients demonstrate a severely impaired capacity for physical work and exercise tolerance, which has been reported to be as low as $50-60 \%$ of that measured in healthy subjects $[8,9]$; the $\mathrm{VO}_{2 \text { peak }}$ of the subjects in the present study was $12.8 \pm 4.2 \mathrm{~mL} / \mathrm{min} / \mathrm{kg}$ (Table 2 ), which is lower than the predictive value for survival, i.e., 17.5 $\mathrm{mL} / \mathrm{min} / \mathrm{kg}$ [20]. Moreover, this study showed that the low exercise tolerance in the HD patients was associated with blood pressure instability over 2 weeks of HD. The blood pressure response is related through various nervous system mechanisms related to the sympathetic nervous system, vasoconstriction, and baroreflex activity. Previous studies have shown that baroreflex sensitivity regulates blood pressure by sensing changes in blood pressure and that a negative feedback [21] has an inverse relationship with exercise tolerance [22]. Additionally, autonomic dysfunction measured by $\mathrm{HR}$ variability in
HD patients was significantly correlated with exercise intolerance during the exercise treadmill test [23]. These studies suggested that exercise intolerance may affect blood pressure instability during HD through inactivity of baroreflex sensitivity and autonomic function.

Autonomic dysfunction is highly prevalent in HD patients [24] and has been implicated in the increased risk of blood pressure instability during $\operatorname{HD}[17,25]$. Indeed, this study showed that the HRR, which reflects parasympathetic activation, was associated with blood pressure instability during HD. The HRR also reflects cardiac parasympathetic activation both in healthy individuals and patients with chronic conditions [26, 27], and HD patients have lower HRRs than healthy control subjects [28]. In 2286 healthy subjects, the HRR showed a significant correlation with exercise tolerance and resting SBP [7]. Additionally, a previous study has shown that patients with IDH demonstrated no significant change in the HR and sympathetic nerve activity as a compensatory response of hypotension and that autonomic dysfunction and increased arterial stiffness contributed to the vascular malfunction in HD patients [13].

Blood pressure instability was associated with exercise load at and peak, not $\mathrm{VO}_{2}$. However, the mechanism behind such is unknown. A previous study has demonstrated that the skeletal muscular mass affects autonomic function [29]. HD patients have a low muscular mass [30] and poor muscular strength [31] in addition to exercise tolerance evaluated by $\mathrm{VO}_{2}[8,9]$. The exercise load might reflect the autonomic activity and blood pressure response better than $\mathrm{VO}_{2}$ because the former might be an index that could assess exercise tolerance, muscular mass, and muscular strength complexity. Further studies are required to further investigate the relationship between exercise tolerance and the blood pressure response during HD.

This study has some limitations. Firstly, this study was based on stable HD patients, not patients with severe IDH episodes. Patients with IDH who have dialysis problems may have different exercise tolerance and blood pressure responses. Secondly, this study has a small sample size; thus, it has not fully excluded confounding factors and could not further elucidate significant factors in multivariate analysis. We have to adjust for the effect of body fluid control measured by body impedance analysis and the influence of intra and/or extra dialytic drugs, diabetes, and sex. In this study, most patients use drugs that affect blood pressure. As this study cannot verify the effects of different drugs, future studies are necessary. The included ratio of diabetic patients of this study is similar to the results of a survey by the Japanese Society for Dialysis Therapy that the ratio of diabetic nephropathy patients was $43.7 \%$. This study cannot adjust for the confounding factor of diabetes, but may be close 
to the population of Japanese dialysis patients. Further studies are required to investigate the relationship between exercise tolerance and the blood pressure response by adjusting for these variables.

\section{Conclusion}

This study investigates the association between the blood pressure response during HD and exercise tolerance or the HRR, which reflects autonomic function. Blood pressure instability during HD is significantly associated with exercise tolerance and the HRR measured using CPX. Exercise intolerance in HD patients may be associated with blood pressure instability through autonomic dysfunction.

\section{Acknowledgements}

Not applicable

\section{Authors' contributions}

HY conceived the study, participated in its design and coordination, and wrote the first draft of the manuscript. KK participated in the design of the study and performed the statistical analyses. KK, RS, and AM measured the data of this study. YM integrated the research data measurements as the measurement manager. HK treated the patients and measured the clinical data as the principal doctor. All authors read and approved the final manuscript.

\section{Funding}

Not applicable.

\section{Availability of data and materials}

Please contact author for data requests.

\section{Ethics approval and consent to participate}

This study conformed to the provisions of the Declaration of Helsinki, and written informed consent was obtained from all participants. The study was approved by the Nagoya Kyoritsu Hospital Ethical Committee (K118-02).

\section{Consent for publication}

Not applicable

\section{Competing interests}

The authors declare that they have no competing interests.

\section{Author details}

${ }^{1}$ Department of Physical Therapy, School of Rehabilitation Sciences, Seirei Christopher University, 3453 Mikatahara, Kita-ku, Hamamatsu 433-8558, Japan. ${ }^{2}$ Department of Rehabilitation, Nagoya Kyoritsu Hospital, Nagoya, Japan ${ }^{3}$ Department of Physical Therapy, International University of Health and Welfare School of Health Sciences at Narita, Narita, Japan. ${ }^{4}$ Department of Health Fitness Program, Nagoya Kyoritsu Hospital, Nagoya, Japan.

${ }^{5}$ Department of Nephrology, Nagoya Kyoritsu Hospital, Nagoya, Japan.

Received: 29 July 2019 Accepted: 30 December 2019

Published online: 09 January 2020

\section{References}

1. Bradshaw W, Ockerby C, Bennett PN. Intradialytic hypotension prevention and management knowledge and practices: results from a survey of Australian and New Zealand nephrology nurses. Nephrol Nurs J. 2015;42: 155-66 quiz 167

2. Henrich WL. Intradialytic hypotension: a new insight to an old problem. Am J Kidney Dis. 2008;52:209-10.

3. Thijssen S, Kappel F, Kotanko P. Absolute blood volume in hemodialysis patients: why is it relevant, and how to measure it? Blood Purif. 2013; 35:63-71.
4. Shoji T, Tsubakihara Y, Fuji M, et al. Hemodialysis-associated hypotension as an independent risk factor for two-year mortality in hemodialysis patients. Kidney Int. 2004;66:1212-20.

5. Daugirdas JT. Pathophysiology of dialysis hypotension: an update. Am J Kidney Dis. 2001;38:S11-7.

6. Hirakata H, Nitta K, Inaba M, et al. Japanese Society for Dialysis Therapy guidelines for management of cardiovascular diseases in patients on chronic hemodialysis. Ther Apher Dial. 2012;16:387-435.

7. Hughes AD, Chaturvedi N. Estimation of maximal oxygen consumption and heart rate recovery using the Tecumseh sub-maximal step test and their relationship to cardiovascular risk factors. Artery Res. 2017;18:29-35.

8. Capitanini A, Cupisti A, Mochi N, et al. Effects of exercise training on exercise aerobic capacity and quality of life in hemodialysis patients. $J$ Nephrol. 2008;21:738-43.

9. Painter $P$. Determinants of exercise capacity in CKD patients treated with hemodialysis. Adv Chronic Kidney Dis. 2009;16:437-48.

10. Lai $\mathrm{KN}, \mathrm{Ng} J$, Whitford J, et al. Left ventricular function in uremia: echocardiographic and radionuclide assessment in patients on maintenance hemodialysis. Clin Nephrol. 1985;23:125-33.

11. Renger A, Muller M, Jutzler GA, et al. Echocardiographic evaluation of left ventricular dimensions and function in chronic hemodialysis patients with cardiomegaly. Clin Nephrol. 1984;21:164-8.

12. Campese VM, Romoff MS, Levitan D, et al. Mechanisms of autonomic nervous system dysfunction in uremia. Kidney Int. 1981;20:246-53.

13. Yamamoto K, Kobayashi N, Kutsuna $T$, et al. Excessive fall of blood pressure during maintenance hemodialysis in patients with chronic renal failure is induced by vascular malfunction and imbalance of autonomic nervous activity. Ther Apher Dial. 2012;16:219-25.

14. JCS Joint Working Group. Guidelines for rehabilitation in patients with cardiovascular disease (JCS 2012). Circ J. 2014:78:2022-93.

15. Stafie ME, Checherit IA, Niculae A, et al. Intradialytic hypotension: mechanisms and therapeutic implications. Ther Pharmacol Clin Toxicol. 2010;14:57-62.

16. Gul A, Miskulin D, Harford A, Zager P. Intradialytic hypotension. Curr Opin Nephrol Hypertens. 2016;25(6):545-50.

17. Rubinger D, Revis N, Pollak A, et al. Predictors of haemodynamic instability and heart rate variability during haemodialysis. Nephrol Dial Transplant. 2004:19:2053-60.

18. Franciosa JA, Park M, Levine TB. Lack of correlation between exercise capacity and indexes of resting left ventricular performance in heart failure. Am J Cardiol. 1981:47:33-9.

19. Yang $\mathrm{NI}$, Wang $\mathrm{CH}$, Hung $\mathrm{MJ}$, et al. Real-time three-dimensional echocardiography provides advanced haemodynamic information associated with intra-dialytic hypotension in patients with autonomic dysfunction. Nephrol Dial Transplant. 2010;25:249-54.

20. Sietsema KE, Amato A, Adler SG, et al. Exercise capacity as a predictor of survival among ambulatory patients with end-stage renal disease. Kidney Int. 2004;65:719-24.

21. Sapoznikov D, Dranitzki Elhalel M, Rubinger D. Heart rate response to blood pressure variations: sympathetic activation versus baroreflex response in patients with end-stage renal disease. PLoS One. 2013;8:e78338.

22. Yuasa F, Sumimoto T, Yokoe H, et al. Relationship between arterial baroreflex sensitivity and exercise capacity in patients with acute myocardial infarction. Clin Physiol Funct Imaging. 2010;30:69-74.

23. Carreira MA, Nogueira AB, Pena FM, et al. Detection of autonomic dysfunction in hemodialysis patients using the exercise treadmill test: the role of the chronotropic index, heart rate recovery, and R-R variability. PLoS One. 2015;10:e0128123.

24. Lugon JR, Warrak EA, Lugon AS, et al. Revisiting autonomic dysfunction in end-stage renal disease patients. Hemodial Int. 2003;7:198-203.

25. Chang YM, Shiao CC, Chang KC, et al. Heart rate variability is an indicator for intradialytic hypotension among chronic hemodialysis patients. Clin Exp Nephrol. 2016;20:650-9.

26. Imai $\mathrm{K}$, Sato $\mathrm{H}$, Hori $\mathrm{M}$, et al. Vagally mediated heart rate recovery after exercise is accelerated in athletes but blunted in patients with chronic heart failure. J Am Coll Cardiol. 1994;24:1529-35.

27. Shetler K, Marcus R, Froelicher VF, et al. Heart rate recovery: validation and methodologic issues. J Am Coll Cardiol. 2001:38:1980-7.

28. Samara AP, Kouidi E, Ouzouni S, et al. Relationship between exercise test recovery indices and psychological and quality-of-life status in hemodialysis patients: a pilot study. J Nephrol. 2013;26:495-501. 
29. Baek J, Park D, Kim I, et al. Autonomic dysfunction of overweight combined with low muscle mass. Clin Auton Res. 2013;23:325-31.

30. Mclntyre CW, Selby NM, Sigrist $M$, et al. Patients receiving maintenance dialysis have more severe functionally significant skeletal muscle wasting than patients with dialysis-independent chronic kidney disease. Nephrol Dial Transplant. 2006;21:2210-6.

31. Fahal IH, Bell GM, Bone JM, et al. Physiological abnormalities of skeletal muscle in dialysis patients. Nephrol Dial Transplant. 1997;12:119-27.

\section{Publisher's Note}

Springer Nature remains neutral with regard to jurisdictional claims in published maps and institutional affiliations.

Ready to submit your research? Choose BMC and benefit from:

- fast, convenient online submission

- thorough peer review by experienced researchers in your field

- rapid publication on acceptance

- support for research data, including large and complex data types

- gold Open Access which fosters wider collaboration and increased citations

- maximum visibility for your research: over $100 \mathrm{M}$ website views per year

At $\mathrm{BMC}$, research is always in progress.

Learn more biomedcentral.com/submissions 